\title{
Pituitary tumor-transforming gene-1 serves as an independent prognostic biomarker for gastric cancer
}

\author{
Mi-die Xu • Lei Dong • Peng Qi • Wei-wei Weng • Xiao-han Shen • \\ Shu-juan Ni $\cdot$ Dan Huang $\cdot$ Cong Tan $\cdot$ Wei-qi Sheng $\cdot$ \\ Xiao-yan Zhou $\cdot$ Xiang Du
}

Received: 22 July 2014/ Accepted: 29 December 2014/Published online: 28 January 2015

(C) The International Gastric Cancer Association and The Japanese Gastric Cancer Association 2015

\begin{abstract}
Background Pituitary tumor-transforming gene-1 (PTTG1) is a transcription factor that can affect transcriptional activity, angiogenesis, and cell senescence. We examined PTTG1 mRNA and protein expression in gastric cancer (GC) cell lines and tissues to determine its value as a biomarker for GC diagnosis and therapy.

Methods PTTG1 mRNA expression from 78 GC cases and paired adjacent normal mucosa (PCR cohort) as well as from five gastric cell lines was assessed using qRT-PCR. Nuclear and cytoplasmic RNA were extracted from two
\end{abstract}

M. Xu and L. Dong contributed equally to this work.

Electronic supplementary material The online version of this article (doi:10.1007/s10120-015-0459-2) contains supplementary material, which is available to authorized users.

M. Xu · L. Dong · P. Qi · W. Weng $\cdot$ X. Shen $\cdot$ S. Ni ·

D. Huang $\cdot$ C. Tan $\cdot$ W. Sheng $\cdot$ X. Zhou $\cdot$ X. Du $(\varangle)$

Department of Pathology, Fudan University Shanghai Cancer

Center, Shanghai 200032, China

e-mail: dx2008cn@163.com

M. Xu

e-mail: xumd27202003@sina.com

M. Xu · L. Dong · P. Qi - W. Weng · X. Shen · S. Ni ·

D. Huang $\cdot$ C. Tan $\cdot$ W. Sheng $\cdot$ X. Zhou $\cdot$ X. Du

Department of Oncology, Shanghai Medical College, Fudan

University, Shanghai 200032, China

M. Xu · L. Dong · P. Qi - W. Weng · X. Shen · S. Ni ·

D. Huang $\cdot$ C. Tan $\cdot$ W. Sheng $\cdot$ X. Zhou $\cdot$ X. Du

Institute of Pathology, Fudan University, Shanghai 200032,

China

X. Du

Institutes of Biomedical Sciences, Fudan University,

Shanghai 200032, China gastric cell lines to determine PTTG1 mRNA localization. PTTG1 protein expression from $98 \mathrm{GC}$ cases, their paired adjacent normal mucosa, and 23 gastric intraepithelial neoplasia (GIN) cases was examined using immunohistochemistry (IHC cohort). The correlation between PTTG1 mRNA and protein expression and GC clinicopathological parameters was analyzed.

Results PTTG1 mRNA expression in GC tissues and cell lines was significantly increased compared with adjacent normal gastric mucosa and normal gastric mucous cell lines $(p<0.05)$. PTTG1 expression was nuclear and cytoplasmic, with higher cytoplasmic expression. PTTG1 immunostaining significantly differed in GC $(95.66 \pm 20.65), \quad$ GIN $(84.00 \pm 34.16)$, and normal adjacent mucosa $(28 \pm 22.25)$ $(p<0.001)$. Multivariate Cox regression analysis revealed that PTTG1 mRNA and protein expression are independent prognostic factors for GC patient survival.

Conclusion Our results suggest that PTTG1 is a promising target for GC diagnosis and therapy.

Keywords Gastric cancer - PTTG1 .

Immunohistochemistry $\cdot$ Prognosis

\section{Introduction}

Although the worldwide gastric cancer (GC) incidence is declining, it remains the second leading cause of cancer mortality worldwide [1]. The overall 5-year survival rate of GC patients ranges from $10 \%$ to $30 \%$ [2]. GC prognosis is related to numerous factors. There has been increasing interest on identifying new prognostic GC biomarkers to predict its biological behavior. Novel biomarkers can also improve treatment design and aid in the development of new therapeutic targets. 
Pituitary tumor-transforming gene-1 (PTTG1), also known as securin, encodes a regulatory protein that participates in cellular pathways involving cell division, chromosome stability, and DNA repair. PTTG1 is a transcription factor that affects transcriptional activity, angiogenesis, and cell senescence by directly binding to DNA or interacting with proteins, including p53, fibroblast growth factor 2, p21, and MMP [3-5]. PTTG1 was originally isolated from rat pituitary tumor cells [6] and was subsequently reported to be overexpressed in a variety of tumors, including pituitary, ovary, colon, lung, breast, adrenal gland, and testis [7-13]. PTTG1 expression is correlated with the biological behavior of various tumors, suggesting its potential as a prognostic biomarker and therapeutic target.

The few available reports concerning PTTG1 expression in GC have shown inconsistent results [14-16]. In the present study, we investigated PTTG1 mRNA and protein expression in GC cell lines and tissues using quantitative real-time polymerase chain reaction (qRT-PCR) and immunohistochemistry (IHC). Our results suggest that PTTG1 overexpression is an independent prognostic GC biomarker.

\section{Methods}

Tissue samples and tissue microarray (TMA)

The fresh tissue samples used in this study were obtained from 78 patients with GC who underwent gastrectomy with lymph node dissection (PCR cohort) and stored at the Fudan University Shanghai Cancer Center tissue bank between 2007 and 2011. Resected cancer tissues and paired adjacent normal mucosa were snap-frozen in liquid nitrogen and stored at $-80^{\circ} \mathrm{C}$ until RNA preparation. Formalin-fixed, paraffin-embedded (FFPE) specimens from $98 \mathrm{GC}$ and $23 \mathrm{GIN}$ cases (IHC cohort) were retrieved from the Department of Pathology of Fudan University Shanghai Cancer Center archives between 2009 and 2011. All case diagnoses were histopathologically confirmed. No patient in this study was treated preoperatively. All GC case clinicopathological features were assessed (Table 1). The average follow-up time was 37.57 months (median, 36 months; range, 4-78 months). The tumor grades were defined in accordance with the criteria outlined by the World Health Organization (WHO) Classification of Tumors of the Digestive System, 2010 edition [17]. Lauren criteria were applied to classify tumors into intestinal type and diffuse type [18]. Tumors were staged according to the criteria enumerated in the AJCC Cancer Staging Manual, seventh edition [19]. The characteristics and descriptive statistics of the fresh tissue cohort and FFPE tissue cohort are listed in
Table 1. This study was approved by The Clinical Research Ethics Committee of Fudan University Shanghai Cancer Center and was performed in accordance with the ethical guidelines of the Declaration of Helsinki.

Cores (1 $\mathrm{mm}$ in diameter) from FFPE blocks were obtained for TMA construction. For each GC case, four cores (two suitable cancer foci and two adjacent normal epithelial foci) were inserted into the recipient paraffin blocks. For GIN cases, two representative cores per case were obtained. Following histological examination, a pathologist determined the locations of all obtained foci.

\section{Cell culture}

Six human GC cell lines, including MGC-803, AGS, HGC27, SGC7901, MKN-45 BGC-823, and a normal human gastric mucous cell line, GES-1, were obtained from the Chinese Academy of Science cell bank or the American Type Culture Collection (Manassas, VA, USA). All cell lines were grown in Dulbecco's modified Eagle's medium supplemented with $10 \%$ fetal bovine serum and $2 \mathrm{mM} \mathrm{L}-$ glutamine (Invitrogen, Carlsbad, CA, USA) at $37^{\circ} \mathrm{C}$ in a $10 \% \mathrm{CO}_{2}$ atmosphere.

\section{Localization}

Nuclear and cytoplasmic RNA were separately extracted from the AGS and SGC7901 cell lines using the PARIS (Protein and RNA Isolation System) Kit (Life Technologies, USA). Briefly, cells were washed with phosphatebuffered saline (PBS) and incubated on ice with cell fractional buffer. Nuclear and cytoplasmic fractions were then separated. RNA was extracted from the separate lysates by adding ethanol. Nuclear and cytoplasmic RNA were converted to cDNA and analyzed by qRT-PCR. Three genes were used as controls. Of the control genes, glyceraldehyde-3-phosphate dehydrogenase (GAPDH) was expressed in both the nucleus and cytoplasm. The mitochondrial gene MT RNR1 was expressed in the cytoplasm, whereas the nuclear transcript U6 was expressed in the nucleus. $\beta$-Actin was used for normalization. The primer sequences are listed in Supplementary Table 1.

\section{Quantitative RT-PCR}

To assess PTTG1 RNA expression, total RNA from tissues of PCR cohort as well as cultured cells was extracted using Trizol (Invitrogen) according to the manufacturer's instructions. Then, the total RNA was reverse transcribed into cDNA using the PrimeScript RT reagent Kit (Takara, Dalian, China). The resulting cDNA was subjected to SYBR Green-based quantitative PCR analysis as 
Table 1 Clinical characteristics of gastric cancer patients
Clinicopathological feature

Cohort 1 (RT-PCR group)

Number (\%)

Cohort 2 (IHC group)

Number $(\%)$

\begin{tabular}{|c|c|c|}
\hline \multicolumn{3}{|l|}{ Age (years) } \\
\hline$<60$ & $36(46.2)$ & $42(42.9)$ \\
\hline$\geq 60$ & $42(53.8)$ & $56(57.1)$ \\
\hline \multicolumn{3}{|l|}{ Gender } \\
\hline Male & $63(80.8)$ & 77 (78.6) \\
\hline Female & $15(19.2)$ & $21(21.4)$ \\
\hline \multicolumn{3}{|l|}{ Tumor mass size } \\
\hline$<5 \mathrm{~cm}$ & $26(33.3)$ & $33(33.7)$ \\
\hline$\geq 5 \mathrm{~cm}$ & $52(66.7)$ & $65(66.3)$ \\
\hline \multicolumn{3}{|l|}{ Location } \\
\hline Upper stomach & $18(23.1)$ & $19(19.4)$ \\
\hline Middle stomach & $21(26.9)$ & $29(29.6)$ \\
\hline Lower stomach & $30(38.5)$ & $35(35.7)$ \\
\hline Entire stomach & $9(11.5)$ & $15(15.3)$ \\
\hline \multicolumn{3}{|l|}{ Histological grade } \\
\hline Well or moderate & $18(23.1)$ & $26(26.5)$ \\
\hline Poor or other & $60(76.9)$ & $72(73.5)$ \\
\hline \multicolumn{3}{|l|}{ Lauren classification } \\
\hline Intestinal type & $41(52.5)$ & $52(53.1)$ \\
\hline Diffuse type & $32(41.0)$ & $42(42.8)$ \\
\hline Mixed type & $5(6.5)$ & $4(4.1)$ \\
\hline \multicolumn{3}{|l|}{ pT stage } \\
\hline pT1 & $5(6.4)$ & $4(4.1)$ \\
\hline pT2 & $12(15.4)$ & $13(13.3)$ \\
\hline pT3 & $11(14.1)$ & $13(13.3)$ \\
\hline pT4 & $50(64.1)$ & $68(69.4)$ \\
\hline \multicolumn{3}{|l|}{ pN stage } \\
\hline pNO & $26(33.3)$ & $19(19.4)$ \\
\hline $\mathrm{pN} 1$ & $5(6.4)$ & $15(15.3)$ \\
\hline $\mathrm{pN} 2$ & $18(23.1)$ & $26(26.5)$ \\
\hline $\mathrm{pN} 3$ & $29(37.2)$ & $38(38.8)$ \\
\hline \multicolumn{3}{|l|}{ Peritoneal metastasis } \\
\hline Absent & $63(80.8)$ & $75(76.5)$ \\
\hline Present & $15(19.2)$ & $23(23.5)$ \\
\hline \multicolumn{3}{|l|}{ Vascular invasion } \\
\hline Absent & $36(46.2)$ & $39(39.8)$ \\
\hline Present & $42(53.8)$ & $59(60.2)$ \\
\hline \multicolumn{3}{|l|}{ Nervous invasion } \\
\hline Absent & $34(43.6)$ & $42(42.9)$ \\
\hline Present & $44(56.4)$ & $56(57.1)$ \\
\hline \multicolumn{3}{|l|}{ Recurrence } \\
\hline Absent & $51(65.4)$ & $55(56.1)$ \\
\hline Present & 27 (34.6) & $43(43.9)$ \\
\hline
\end{tabular}

$R T-P C R$ real-time polymerase chain reaction, $I H C$ immunohistochemistry calculated using the comparative cycle threshold $(\mathrm{Ct})$ $\left(2^{-\Delta \Delta \mathrm{CT}}\right)$ method. GAPDH was used as the endogenous control for data normalization. The primer sequences are listed in Supplementary Table 1. 
Immunohistochemistry and scoring

Sections $4 \mu \mathrm{m}$ thick were dewaxed and rehydrated using xylene and ethanol. Heat-induced antigen retrieval was performed in a pressure cooker. Then, the sections were incubated with anti-PTTG1 antibody (1:300) (ABS511; Millipore, USA) overnight at $4{ }^{\circ} \mathrm{C}$. The secondary antibody (PV 9000; Beijing Zhongshan Bio-tech, China) was incubated for $30 \mathrm{~min}$ to visualize positive signals. The appropriate positive and negative controls were also stained. Positive staining was observed in the nucleus and cytoplasm. For noninformative TMA samples (i.e., samples with $<500$ tumor cells per case, lost samples, or samples with too few tumor cells), IHC staining was analyzed using whole tissue slides. The " $H$-Score" [21] was determined to evaluate immunoreactivity. Briefly, more than 200 tumor cells were independently evaluated in each case by two authors. For each section, the stain intensity was scored as 0,1 , or 2 corresponding to the presence of negative, weak, and strong brown staining, respectively. The final score of a section was generated using the following formula: $H$ score $=0 \times(\%$ of negative cells $)+1 \times(\%$ of weakly stained cells $)+2 \times(\%$ of strongly stained cells $)$. Finally, a score within the range of 0 to 200 was obtained.

\section{Statistical analyses}

When there were two experimental groups, statistical significance was analyzed using Student's $t$ test, the Pearson $\chi^{2}$ test, and the Wilcoxon test. When there were more than two groups, one-way analysis of variance (ANOVA) was used to evaluate the data. Variables with a $p$ value $<0.05$ in the univariate analysis were used in the subsequent multivariate analysis using the Cox proportional hazards model. Survival rates were calculated using the Kaplan-Meier

a

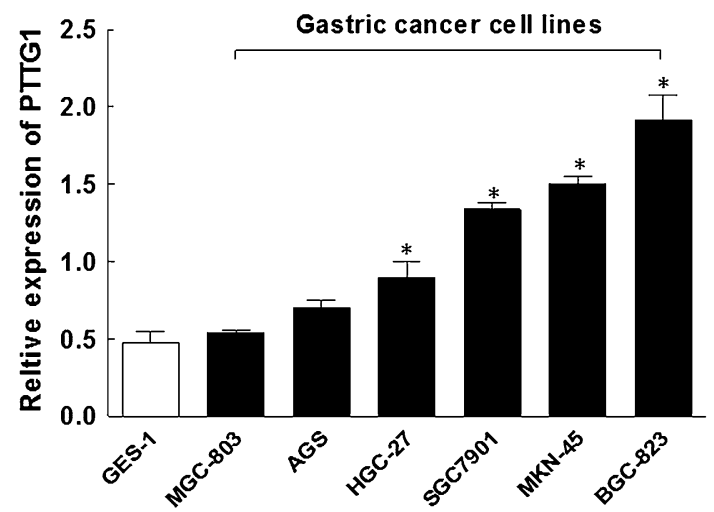

Fig. 1 Pituitary tumor-transforming gene-1 (PTTG1) mRNA expression in cell lines. a PTTG1 mRNA expression was significantly increased in four gastric carcinoma (GC) cell lines compared with the method with log-rank test performed for comparisons. Two-sided $p$ values were used, and $p<0.05$ was considered statistically significant. All analyses were performed using SPSS 20.0 software (IBM, SPSS, Chicago, IL, USA).

\section{Results}

PTTG1 mRNA expression in cell lines and tissues

We initially detected PTTG1 mRNA expression in gastric cell lines using qRT-PCR. Compared with the normal gastric mucous cell line GES-1, four of six GC cell lines had significantly increased PTTG1 expression $(p<0.001)$. No significant differences were observed for MGC-803 $(p=0.424)$ and AGS $(p=0.056)$ (Fig. 1a). In tissues obtained from 78 GC patients, PTTG1 mRNA expression in cancer tissues from 57 patients was significantly increased compared with the adjacent normal gastric mucosa tissue $(p<0.0001)$ (Fig. 2a, b).

\section{PTTG1 mRNA localization}

The three control genes, GAPDH, MT RNR1, and U6, displayed the expected expression patterns (Fig. 1b) in AGS and SGC7901 cell lines. PTTG1 was expressed in the nuclear and cytoplasmic fractions. The ratio of cytoplasmic expression to nuclear expression averaged 1.5. These results suggest that PTTG1 exhibits nuclear and cytoplasmic expression, with slightly higher cytoplasmic expression.

\section{IHC}

PTTG1 protein expression in GC, normal adjacent mucosa, and GIN tissues of PCR cohort was evaluated using IHC.

b

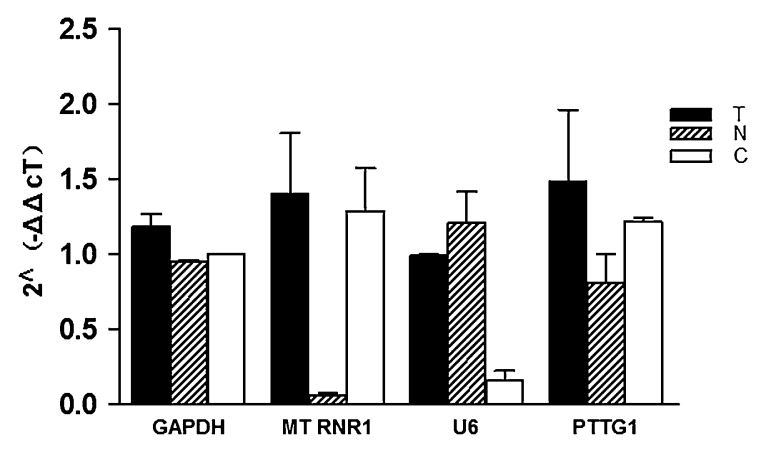

normal gastric mucous cell line. b PTTG1 was localized to the nucleus and cytoplasm. Three control genes and PTTG1 expression in total ( $T)$ RNA, nuclear $(N)$ RNA, and cytoplasmic $(C)$ RNA 


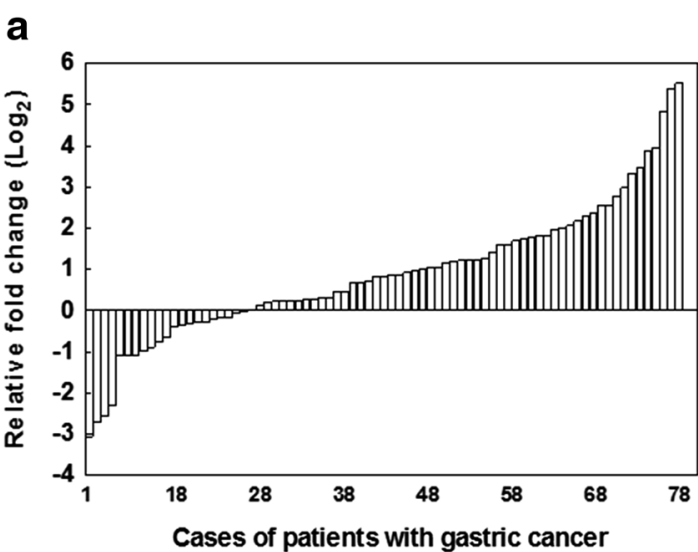

Fig. 2 PTTG1 mRNA expression in GC and adjacent normal tissues. a PTTG1 was significantly overexpressed in cancerous tissues relative to their adjacent normal mucosa in $78 \mathrm{GC}$ patients. Expression levels

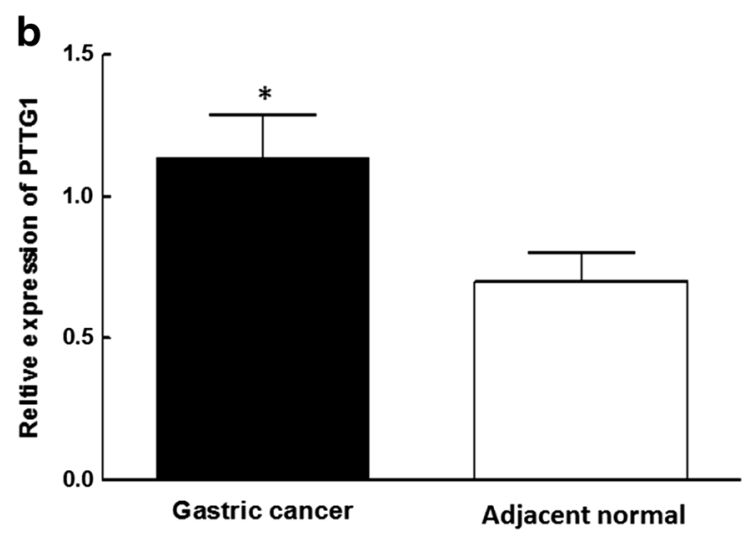

are presented as log twofold change from adjacent normal tissue. b PTTG1 expression in GC cases was significantly higher than adjacent normal mucosa. ${ }^{*} p<0.05$
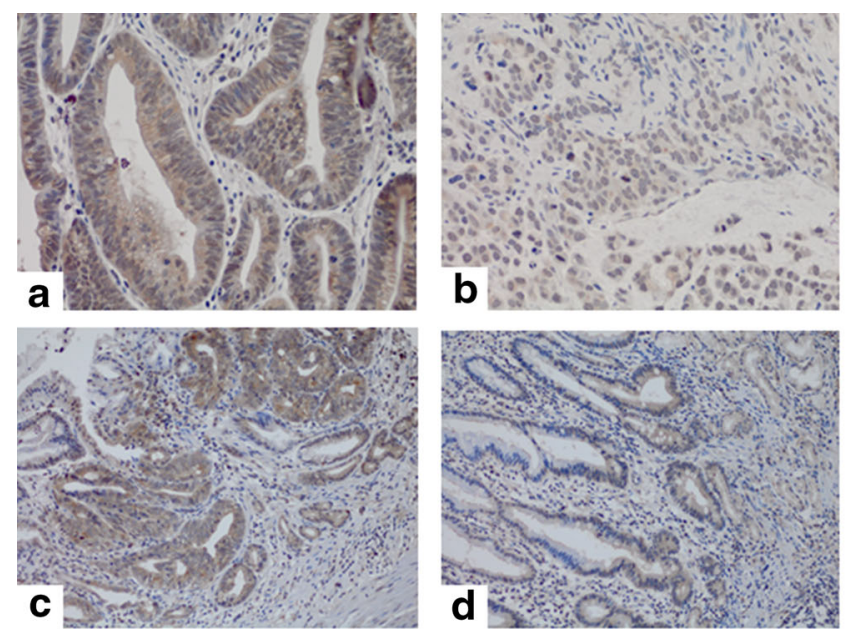

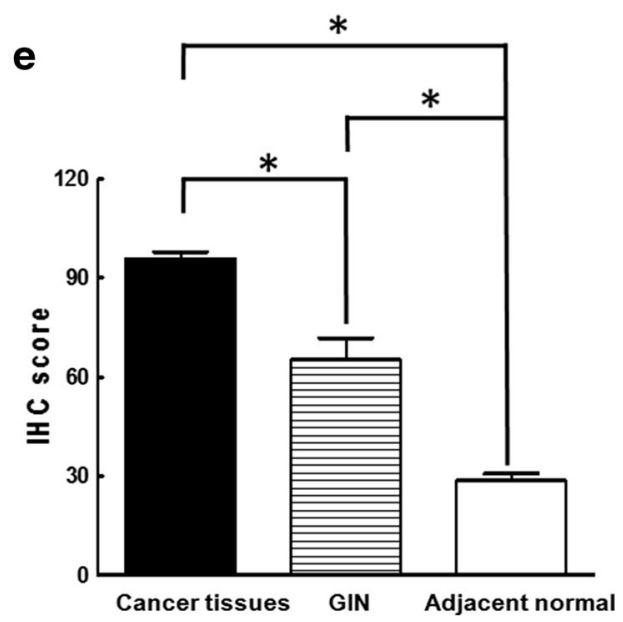

intensity indicate strong (a) and weak (b) staining in GC, strong staining in GIN (c), and weak staining in adjacent normal mucosa (d)

lymphocytes that infiltrated in the stroma were PTTG1 positive.

Correlation and Cox regression analysis

The correlation analysis determined that no gastric clinicopathological parameters correlated with PTTG1 mRNA and protein expression $(p>0.05$; Table 2$)$. PTTG1 expression levels in tumor tissues were categorized as low or high relative based on the Youden's index. The KaplanMeier analysis determined that the mean survival time for GC patients with low PTTG1 mRNA expression levels was 62.6 months compared with 34.8 months for patients with high PTTG1 mRNA expression $(p<0.0001$, log-rank test; Fig. 5, Table 2). Cytoplasmic PTTG1 protein staining also showed the mean survival time of patients with a low score (60.20 months) was longer than that of those with a high 
Fig. 4 Nuclear PTTG1 protein expression in GC, GIN (GIN), and adjacent normal mucosa. Representative photographs of anti-PTTG1 antibody nuclear staining intensity show (arrows) scattered positive nuclei in GC

(a) and GIN (b). IHC immunohistochemistry
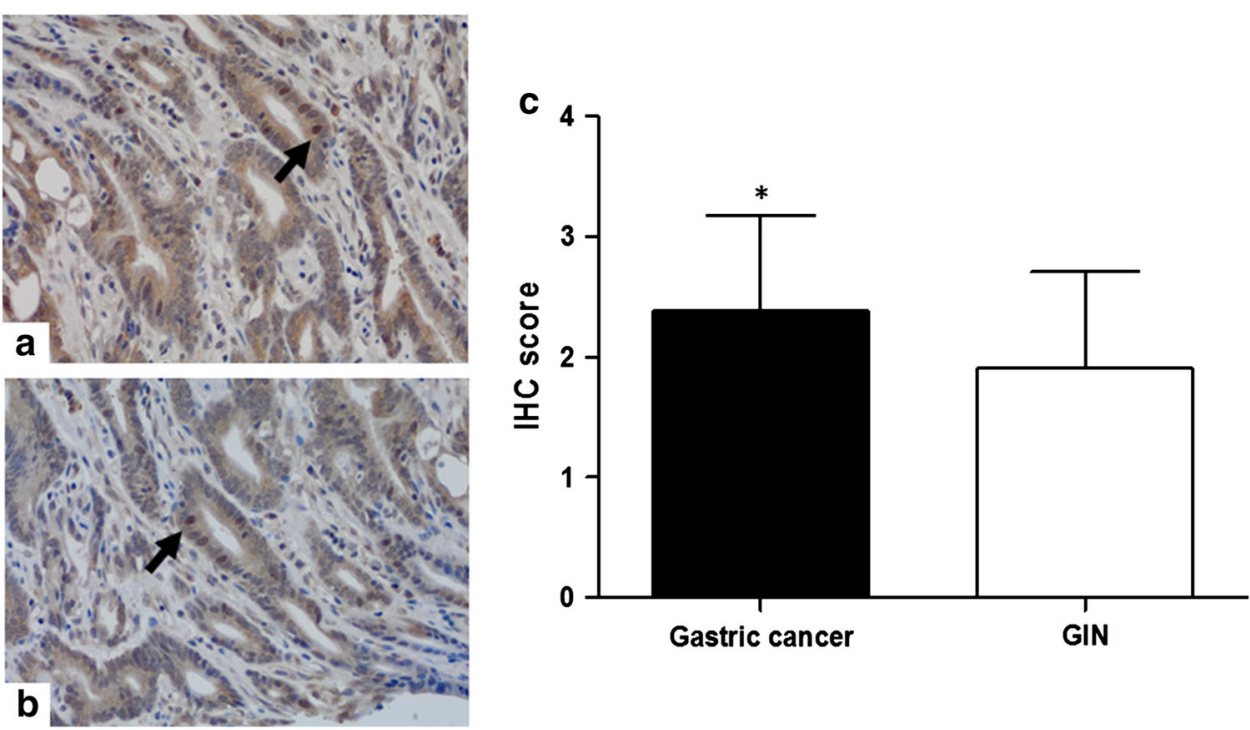

Table 2 Univariate and multivariate analyses of clinicopathological factors for disease-specific survival in gastric cancer patients (PCR cohort)

\begin{tabular}{|c|c|c|c|c|}
\hline \multirow[t]{2}{*}{ Variable } & \multicolumn{2}{|l|}{ Univariate analysis } & \multicolumn{2}{|l|}{ Multivariate analysis } \\
\hline & $\mathrm{HR}(95 \% \mathrm{CI})$ & $p^{\mathrm{a}}$ & $\operatorname{HR}(95 \% \mathrm{CI})$ & $p^{\mathrm{a}}$ \\
\hline Age $(\geq 60 /<60)$ (years) & $1.711(0.862-3.396)$ & 0.125 & & \\
\hline Gender (male/female) & $0.821(0.455-1.484)$ & 0.515 & & \\
\hline Tumor size $(\geq 5 /<5)$ & $1.964(1.071-3.601)$ & 0.029 & & \\
\hline Tumor location (diffuse/upper, middle, lower) & $1.110(0.806-1.527)$ & 0.523 & & \\
\hline Histological grade (poor, other/well, mod) & $1.448(0.610-2.164)$ & 0.669 & & \\
\hline Lauren classification (intestinal/diffuse) & $1.457(0.784-2.707)$ & 0.234 & & \\
\hline Depth of tumor (T3, T4/T1, T2) & $1.875(1.222-2.875)$ & 0.004 & & \\
\hline Vascular invasion (present/absent) & $1.819(0.969-3.415)$ & 0.063 & & \\
\hline Nervous invasion (present/absent) & $2.338(1.217-4.490)$ & 0.011 & & \\
\hline Lymphatic metastasis (present/absent) & $3.837(1.696-8.680)$ & 0.001 & & \\
\hline Peritoneal metastasis (present/absent) & $2.216(1.133-4.335)$ & 0.020 & & \\
\hline TNM stage $(\mathrm{III}+\mathrm{IV} / \mathrm{I}+\mathrm{II})$ & $5.424(2.387-12.327)$ & 0.000 & $7.705(3.232-18.369)$ & 0.000 \\
\hline PTTG1 mRNA (high/low) & $3.146(1.506-6.570)$ & 0.002 & $4.470(2.051-9.742)$ & 0.000 \\
\hline
\end{tabular}

$H R$ hazard ratio, $C I$ confidence interval

${ }^{\text {a }}$ All statistical tests were two sided; significance level $p<0.05$

score (39.18 months). Correlation analyses did not reveal any significant correlations between PTTG1 immunoreactivity and clinicopathological parameters. Furthermore, the multivariate Cox regression analysis determined that both PTTG1 mRNA (Table 2) and protein (Supplementary Table 2) expression is an independent prognostic variable for GC patient survival.

\section{Discussion}

In human normal tissues, PTTG1 mRNA is strongly expressed in adult testis and thymus, whereas it is weakly expressed in colon, small intestine, brain, placenta, and pancreas [6]. As a mammalian securin, PTTG1 protein acts as an inhibitor of separase, a protease that regulates the separation of sister chromatids during mitosis [22]. PTTG1 overexpression is associated with increased invasion, metastasis, and vascularity in various tumor types [23]. Therefore, PTTG1 is considered an oncogene, and a recent study revealed that it acts as a tumor suppressor gene in breast cancer [24]. PTTG1 mediated this tumor suppression activity by inducing chromosome instability, genetic instability, and the expression of other oncogenes [25].

PTTG1 is thought to perform its function in the nucleus. However, cytoplasmic PTTG1 has been observed in 

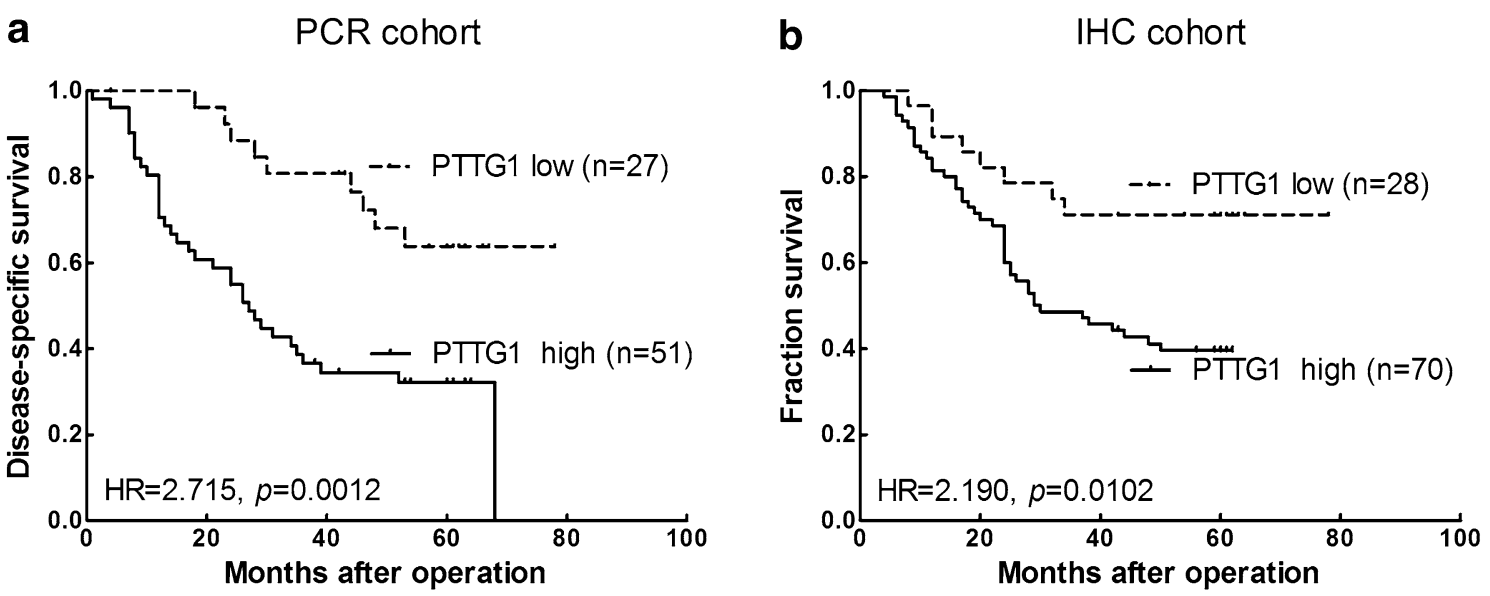

Fig. 5 Kaplan-Meier survival curves stratified by PTTG1 expression level in polymerase chain reaction (PCR) cohort and immunohistochemistry (IHC) cohort. The $p$ value was calculated using the log-rank test. $H R$ hazard ratio

various cell lines and tumor types [26, 27]. The mitogenactivated protein kinase (MAPK) pathway and PTTGbinding factor $(\mathrm{PBF})$ are reportedly involved in the translocation of PTTG from the cytoplasm to the nucleus [28, 29]. In gastric cell lines, we observed that PTTG1 protein was primarily expressed in the cytoplasm but that it was also expressed in the nucleus. Consistently, PTTG1 antibody immunostaining was predominantly cytoplasmic but also nuclear in GC and GIN tissues.

In the present study, using GAPDH as the normalization control, we determined that PTTG1 mRNA expression levels in tumor tissues from 78 GC cases were significantly higher than in the corresponding adjacent normal gastric mucosa tissue. Some of the tumor samples in this study may be contaminated by stroma. However, compared to the highly expressed PTTG1 in gastric glands and tumor cells, the PTTG1 negative fibrous tissue and scattered positive lymphocytes $(<5 \%)$ will not interfere the result of statistical analysis. In the six human GC cell lines, four cell lines exhibited significantly higher PTTG1 mRNA expression than their lower counterparts. Consistent with the mRNA expression data, PTTG1 immunostaining, both in cytoplasm and in nucleus, revealed significantly higher expression in GC tissues compared with adjacent normal gastric mucosa. PTTG1 immunostaining in GIN tissues was increased compared with adjacent normal gastric mucosa and reduced compared with GC tissues, which suggests that PTTG1 protein expression increases during GC development. These results also suggest that PTTG1 is a potential biomarker for GC diagnosis.

PTTG1 overexpression is correlated with tumor invasion, metastasis [23, 30], poor survival [12], and histological grades [31] in various cancers. In contrast to these reports, our study failed to discover a significant correlation between gastric clinicopathological parameters and PTTG1
mRNA and protein expression. Cox regression analysis determined that PTTG1 mRNA expression is an independent factor for predicting GC survival.

Three previous studies have investigated PTTG1 expression in GC with inconsistent results. Of these studies, Yamada et al. reported no significant difference in PTTG1 mRNA expression between GC and noncancerous gastric mucosa [16]. The sampling method, which was not described in detail, or other factors, such as small sample size (only 30 cases), might have contributed to their negative result. The other two studies examined PTTG1 expression in GC using immunohistochemistry [14, 15]. Consistent with our results, these groups reported PTTG1 overexpression in GC. In addition, the studies indicated that PTTG1 expression correlated with differentiation, clinical classification, lymph node metastasis, and histological type or the infiltration depth in GC; however, our results did not support these correlations. This discrepancy may be the result of the use of different antibody clones and scoring methods. Further investigation is needed to confirm the relationship between PTTG1 and GC clinical features.

Published studies have not reported PTTG1 expression in GIN, a precancerous lesion. In the present study, our results revealed that PTTG1 protein expression levels in cancer tissues were higher than intraepithelial neoplasia tissues. Moreover, PTTG1 protein expression levels in intraepithelial neoplasia were increased compared with adjacent normal tissues. These results suggest that PTTG1 expression increases during the malignant transformation process and suggests that PTTG1 may contribute to tumorigenesis and progression. These results reveal the potential utility of PTTG1 as a therapeutic target.

In summary, we present evidence that significant PTTG1 overexpression, both at the mRNA and protein 
levels, occurs in GC cells in vitro and in vivo. Elevated PTTG1 expression in GIN and cancer suggests that PTTG1 might have a potential role in early cancer diagnosis. PTTG1 mRNA expression is also an independent prognostic GC biomarker. Our results indicate that PTTG1 might serve as a promising target for GC diagnosis and therapy.

Acknowledgments This study was supported by National Clinical Key Discipline (2013-2015), Priority of Shanghai Key Discipline of Medicine (2013-2015), Shanghai R\&D public service platform construction projects (12DZ2295100), National Natural Science Foundation of China (81071791), Clinical Key Discipline Fund by Ministry of Health (2010-2012), Academic Award for Doctoral Candidates by Ministry of Education (2012), Mingdao Fund for Medical Graduate Student by Shanghai Medical College (2013), and Shanghai Science and Technology Development Fund (Basic Research Major Project, No. 10DJ1400500).

Conflict of interest The authors declare that they have no competing interests.

\section{References}

1. Kamangar F, Dores GM, Anderson WF. Patterns of cancer incidence, mortality, and prevalence across five continents: defining priorities to reduce cancer disparities in different geographic regions of the world. J Clin Oncol. 2006;24(14):2137-50.

2. De Vita F, Giuliani F, Galizia G, Belli C, Aurilio G, Santabarbara G, Ciardiello F, Catalano G, Orditura M. Neo-adjuvant and adjuvant chemotherapy of gastric cancer. Ann Oncol 2007;18(suppl 6):vi120-vi123

3. Malik MT, Kakar SS. Regulation of angiogenesis and invasion by human pituitary tumor transforming gene (PTTG) through increased expression and secretion of matrix metalloproteinase-2 (MMP-2). Mol Cancer. 2006;5:61.

4. Salehi F, Kovacs K, Scheithauer BW, Lloyd RV, Cusimano M. Pituitary tumor-transforming gene in endocrine and other neoplasms: a review and update. Endocr Relat Cancer. 2008;15(3):721-43.

5. Xie K, Wei D, Huang S. Transcriptional anti-angiogenesis therapy of human pancreatic cancer. Cytokine Growth Factor Rev. 2006;17(3):147-56.

6. Pei L, Melmed S. Isolation and characterization of a pituitary tumor-transforming gene (PTTG). Mol Endocrinol. 1997;11(4):433-41.

7. Zhang X, Horwitz GA, Heaney AP, Nakashima M, Prezant TR, Bronstein MD, Melmed S. Pituitary tumor transforming gene (PTTG) expression in pituitary adenomas. J Clin Endocrinol Metab. 1999;84(2):761-7.

8. Panguluri SK, Yeakel C, Kakar SS. PTTG: an important target gene for ovarian cancer therapy. J Ovarian Res. 2008;1(1):6.

9. Heaney AP, Singson R, McCabe CJ, Nelson V, Nakashima M, Melmed S. Expression of pituitary-tumour transforming gene in colorectal tumours. Lancet. 2000;355(9205):716-9.

10. Rehfeld N, Geddert H, Atamna A, Rohrbeck A, Garcia G, Kliszewski S, Neukirchen J, Bruns I, Steidl U, Fenk R, et al. The influence of the pituitary tumor transforming gene-1 (PTTG-1) on survival of patients with small cell lung cancer and non-small cell lung cancer. J Carcinog. 2006;5:4.
11. Ghayad SE, Vendrell JA, Bieche I, Spyratos F, Dumontet C, Treilleux I, Lidereau R, Cohen PA. Identification of TACC1, NOV, and PTTG1 as new candidate genes associated with endocrine therapy resistance in breast cancer. J Mol Endocrinol. 2009;42(2):87-103.

12. Demeure MJ, Coan KE, Grant CS, Komorowski RA, Stephan E, Sinari S, Mount D, Bussey KJ. PTTG1 overexpression in adrenocortical cancer is associated with poor survival and represents a potential therapeutic target. Surgery (St. Louis). 2013;154(6):1405-16.

13. Pierconti F, Milardi D, Martini M, Grande G, Cenci T, Gulino G, Larocca LM, Rindi G, Pontecorvi A, De Marinis L. Pituitarytumour-transforming-gene 1 expression in testicular cancer. Andrologia 2014. doi:10.1111/and.12283

14. Luo Z, Li B, Chen J, Ma Y, Tao H. Expression and the clinical significance of hPTTG1 in gastric cancer. Mol Med Rep. 2013;7(1):43-6.

15. Wen CY, Nakayama T, Wang AP, Nakashima M, Ding YT, Ito M, Ishibashi H, Matsuu M, Shichijo K, Sekine I. Expression of pituitary tumor transforming gene in human gastric carcinoma. World J Gastroenterol. 2004;10(4):481-3.

16. Yamada M, Asanuma K, Yagihashi A, Nakamura M, Kameshima $\mathrm{H}$, Kobayashi D, Watanabe N. Human pituitary tumor transforming gene 1 (hPTTG1) in gastric mucosal tissues. Am J Gastroenterol. 2001;96(4):1313-4.

17. Lauwers GY, Franceschi S, Carneiro F, Montgomery E, Graham DY, Tatamatsu M, et al. Gastric carcinoma. In: Bosman FT, Carneiro F, Hruban RH, Theise ND, editors. WHO classification of tumours of the digestive system, 4th edn. Lyon: IARC; 2010. pp 48-59

18. Lauren $P$. The two histological main types of gastric carcinoma. Acta Pathol Microbiol Scand. 1965;64:31-49.

19. Edge SBD, Compton C. AJCC cancer staging manual. New York: Springer; 2010.

20. Qi P, Xu MD, Ni SJ, Huang D, Wei P, Tan C, Zhou XY, Du X. Low expression of LOC285194 is associated with poor prognosis in colorectal cancer. J Transl Med. 2013;11(1):122.

21. Thike AA, Chng MJ, Fook-Chong S, Tan PH. Immunohistochemical expression of hormone receptors in invasive breast carcinoma: correlation of results of $\mathrm{H}$-score with pathological parameters. Pathology. 2001;33(1):21-5.

22. Zou H, McGarry TJ, Bernal T, Kirschner MW. Identification of a vertebrate sister-chromatid separation inhibitor involved in transformation and tumorigenesis. Science. 1999;285(5426):418-22.

23. Yan S, Zhou C, Lou X, Xiao Z, Zhu H, Wang Q, Wang Y, Lu N, He S, Zhan Q, et al. PTTG overexpression promotes lymph node metastasis in human esophageal squamous cell carcinoma. Cancer Res. 2009;69(8):3283-90.

24. Hatcher RJ, Dong J, Liu S, Bian G, Contreras A, Wang T, Hilsenbeck SG, Li Y, Zhang P. Pttg1/securin is required for the branching morphogenesis of the mammary gland and suppresses mammary tumorigenesis. Proc Natl Acad Sci USA. 2014;111(3):1008-13.

25. Tong Y, Eigler T. Transcriptional targets for pituitary tumortransforming gene-1. J Mol Endocrinol. 2009;43(5):179-85.

26. Kim DS, Franklyn JA, Smith VE, Stratford AL, Pemberton HN, Warfield A, Watkinson JC, Ishmail T, Wakelam MJ, McCabe CJ. Securin induces genetic instability in colorectal cancer by inhibiting double-stranded DNA repair activity. Carcinogenesis (Oxf). 2007;28(3):749-59.

27. Akino K, Akita S, Mizuguchi T, Takumi I, Yu R, Wang XY, Rozga J, Demetriou AA, Melmed S, Ohtsuru A, et al. A novel molecular marker of pituitary tumor transforming gene involves in a rat liver regeneration. J Surg Res. 2005;129(1):142-6.

28. Chien W, Pei L. A novel binding factor facilitates nuclear translocation and transcriptional activation function of the 
pituitary tumor-transforming gene product. J Biol Chem. 2000;275(25):19422-7.

29. Pei L. Activation of mitogen-activated protein kinase cascade regulates pituitary tumor-transforming gene transactivation function. J Biol Chem. 2000;275(40):31191-8.

30. Solbach C, Roller M, Fellbaum C, Nicoletti M, Kaufmann M. PTTG mRNA expression in primary breast cancer: a prognostic marker for lymph node invasion and tumor recurrence. Breast. 2004;13(1):80-1.

31. Wondergem B, Zhang Z, Huang D, Ong CK, Koeman J, Hof DV, Petillo D, Ooi A, Anema J, Lane B, et al. Expression of the PTTG1 oncogene is associated with aggressive clear cell renal cell carcinoma. Cancer Res. 2012;72(17):4361-71. 